UDC 616.12-005.4:616.132.2-004.6]--073.7

DOI: $10.15587 / 2519-4798.2021 .241534$

\title{
IMPACT OF RANOLAZINE ON EXERCISE TOLERANCE AND ARRHYTHMIAS IN PATIENTS WITH INOCA
}

\author{
Vira Tseluyko, Tetiana Pylova
}

The aim of the study to evaluate the effect of supplementation of basic therapy by ranolazine in patients with INOCA on exercise test parameters and Holter ECG monitoring.

Materials and methods. 53 patients with stable coronary heart disease were examined, including 18 men (33.9\%) and $35(66 \%)$ women, the average age of patients was 57 ( \pm 9.68$)$ years. According to the results of coronary angiography all patients had non-obstructive coronary arteries. In addition to physical and laboratory examination, bicycle ergometry, Holter ECG monitoring and echocardiography were included in the examination of patients. Patients were divided into 2 groups: group I - patients who in addition to standard therapy received ranolazine at a dose of $1000 \mathrm{mg}$ twice a day for 6 months, and group II patients with standard coronary heart disease therapy. After 6 months from the beginning of the observation an objective examination, echocardiography, exercise test, Holter ECG monitoring were repeated.

Results. The study found that patients receiving ranolazine in addition to standard therapy had a statistically significant increase in exercise duration after 6 months compared with baseline and group II. Before treatment in group I, the duration of the exercise test was 356.51 $\pm 180.24 \mathrm{~s}$, and after treatment $414.32 \pm 142.10 \mathrm{~s}(p=0.03)$. In group II, the duration of the test before treatment was $361.4 \pm 160.24 \mathrm{c}$, and after $380.5 \pm 152.2 \mathrm{~s}(\mathrm{p}=0.15)$. It was also found that the duration of the test differed significantly in group I after treatment of patients from group II after treatment of patients with a standard treatment regimen $(p=0.04)$. According to the results of Holter ECG monitoring in group I found a positive effect of ranolazine on the frequency of ventricular arrhythmias: before treatment $n=1142$ [30; 2012], after treatment $n=729$ [23; 1420], while in group II a significant difference between the number of extrasystoles before treatment and after not detected ( $n=1026$ [17; 1920], $n=985$ [15; 1680], respectively) $p=0.18$.

Conclusions. The addition of ranolazine to the basic therapy of patients with non-obstructive coronary arteries disease helps to increase exercise tolerance (according to the loading stress test) and contributes to a significant reduction in the number of ventricular arrhythmias (according to Holter-ECG) compared with both baseline and group II

Keywords: coronary heart disease, INOCA, ranolazine, stress test

How to cite:

Tseluyko, V., Pylova, T. (2021). Impact of ranolazine on exercise tolerance and arrhythmias in patients with INOCA. ScienceRise: Medical Science, 5 (44), 10-15. doi: http://doi.org/10.15587/2519-4798.2021.241534

(C) The Author(s) 2021

This is an open access article under the Creative Commons CC BY license hydrate

\section{Introduction}

The causes of myocardial ischemia in patients with coronary heart disease are very heterogeneous and associated with both functional and morphological changes of epicardial vessels and microvascular dysfunction. The results of the introduction of modern invasive and non-invasive diagnostic methods indicate that the proportion of patients with microcirculatory disorders is quite large $[1,2]$. Therefore, such angina may be a consequence of existing coronary microvascular dysfunction [3]. Angina pectoris with no-obstructive coronary arteries (INOCA) is a major diagnostic dilemma in the daily practice of physician [4]. In the long range, patients with INOCA have a high risk of developing myocardial infarction and an increased incidence of hospitalization associated with heart failure [5]. According to the data, there are studies that confirm the fact that INOCA is associated with a poor prognosis for life, which indicates the importance of rational treatment [6]. Treatment with traditional antianginal drugs, beta-blockers, long-acting nitrates - does not always lead to improved quality of life [7]. Therefore, it is important to investigate the effects of additional anti-ischemic drugs with different mechanisms of action to control symptoms in patients with INOCA, one of which is ranolazine. Ranolazine is an antianginal drug that does not affect the main hemodynamically parameters of the cardiovascular system, but inhibits the activity of sodium in cardiomyocytes in ischemic conditions as a result, this effect reduces intracellular sodium and calcium overload. This mechanism of action improves myocardial relaxation, diastolic function and has a positive effect on myocardial contractility and perfusion [8].

Despite this, no clear global and local guidelines for the management of such patients in clinical practice. In order to improve the management of patients with 
INOCA, it was proposed to evaluate the effect of ranolazine in the management of patients with INOCA on the basis of available literature and practical data, which was the goal of our task.

The aim. To evaluate the effect of supplementation of basic therapy by ranolazine in patients with INOCA on exercise test parameters and Holter ECG monitoring.

\section{Materials and methods}

The study included patients with stable coronary heart disease, men - $18(33.9 \%)$ and $35(66 \%)$ women, the mean age of patients was $57( \pm 9.68)$ years, who were hospitalized in the period from October 2018 to February 2021 to the "City Clinical Hospital No. 8" of the Kharkiv City Council and according to the results of coronary angiography (CAG) had no-obstructive coronary arteries. In all patients, general clinical and instrumental research methods were performed in accordance with the standards for the diagnosis of coronary heart disease [9].

The study was approved by the Bioethics Committee of the Kharkiv Medical Academy of Postgraduate Education (Protocol No. 3 of September 14, 2021) in accordance with the Code of Ethics of the World Medical Association (Helsinki Declaration). All patients included in the study provided written informed consent.

Groups of patients with coronary heart disease with INOCA were comparable according to clinical and anamnestic data (Table 1).

Table 1

Clinical and anamnestic characteristics of the examined groups

\begin{tabular}{|l|c|c|}
\hline \multicolumn{1}{|c|}{ Parameters } & $\begin{array}{c}\text { Group I } \\
\mathrm{n}=16\end{array}$ & $\begin{array}{c}\text { Group II } \\
\mathrm{n}=37\end{array}$ \\
\hline Age, years $(\mathrm{M} \pm \sigma)$ & $55.75 \pm 9.7$ & $57.7 \pm 9.94$ \\
\hline Women $(\mathrm{n} / \%)$ & $11 / 68.75$ & $24 / 64.8$ \\
\hline $\begin{array}{l}\text { Arterial Hypertension } \\
(\mathrm{n} / \%)\end{array}$ & $12 / 75$ & $26 / 70$ \\
\hline Diabetes Mellitus (n/ \%) & $3 / 18.75$ & $5 / 13.5$ \\
\hline Smoking (n/ \%) & $4 / 25$ & $7 / 18.9$ \\
\hline $\begin{array}{l}\text { Myocardial Infarction } \\
(\mathrm{n} / \%)\end{array}$ & $6 / 37.5$ & $10 / 27$ \\
\hline Stroke $(\mathrm{n} / \%)$ & $1 / 6.25$ & $2 / 5.4$ \\
\hline BMI, kg/m 2 & $28.26 \pm 4.0$ & $27.81 \pm 3.38$ \\
\hline
\end{tabular}

CAG was performed mainly by right transradial access, by the method of selective catheterization of coronary artery (CA) on the TOSHIBA INFX-8000C (Japan) with software according to the generally accepted method. The presence of hemodynamically significant stenosis was assessed according to the AHA classification [10]. Holter electrocardiogram monitoring (Holter ECG) was performed using a device model 3225 "DIAKARD" (ATZT "Solveig", Ukraine). Analysis of ST segment deviations relative to isoline and arrhythmias was performed automatically according to generally accepted criteria. The Holter ECG monitoring was used to assess the presence and number of ischemia episodes, the occurrence of arrhythmias, and the number and duration of ischemia. All patients underwent stress test to verify the functional class of stable angina and establish the exercise tolerance. The research was performed on a bicycle ergometer model "Kettler" (Germany), in the morning 1.5-2 hours after a light breakfast, air temperature of $18-20^{\circ} \mathrm{C}$ according to the method of O. Y. Zharinov [11, 12]. Echocardiography was performed on a Sonoline G40 device (Siemens, Germany) during hospitalization. The sizes of the left and right auricles (LA and RA), right ventricle (RV), left ventricular (LV) diastolic diameter (LVDD), left ventricular (LV) systolic diameter (LVSD), left ventricle systolic volume (LVSV) and left ventricle diastolic volume (LVDV), posterior wall thickness (PWS) LV and septal wall thickness (SWS) in diastole, aortic diameter and ejection fraction (EF) according to Simpson EF=(LVDV - LVSV) / LVDV x100\%.

All patients were prescribed standard treatment (Tab. 2) according to the recommendations of the Working Group on Atherosclerosis and Chronic Coronary Heart Diseases of the Association of Cardiologists of Ukraine according to the Unified Clinical Protocol of Primary, Secondary (Specialized) and Tertiary (Highly Specialized) Medical Care "Stable Ischemic Heart Disease" Ministry of Health of Ukraine 02.03.2016 No. 152 (as amended 23.09.2016 No. 994)) and Adapted clinical guidelines "Stable coronary heart disease" (2016); [9].

Table 2

Therapy of examined patients

\begin{tabular}{|l|c|c|}
\hline \multicolumn{1}{|c|}{ Drugs } & $\begin{array}{c}\text { Group I } \\
\mathrm{n}=16\end{array}$ & $\begin{array}{c}\text { Group II } \\
\mathrm{n}=37\end{array}$ \\
\hline B-blockers (n/ \%) & $15 / 93.75$ & $35 / 94.6$ \\
\hline ACE inhibitors (n/ \%) & $12 / 75$ & $30 / 81.08$ \\
\hline Statins (n/ \%) & $16 / 100$ & $37 / 100$ \\
\hline $\begin{array}{l}\text { Anti-Platelet/ Anticoagu- } \\
\text { lant Therapy (n/ \%) }\end{array}$ & $16 / 100$ & $37 / 100$ \\
\hline $\begin{array}{l}\text { Calcium Channel Blockers } \\
(\mathrm{n} / \%)\end{array}$ & $6 / 37.5$ & $7 / 40.5$ \\
\hline
\end{tabular}

Patients were randomized to 2 groups: group I included 16 patients who received ranolazine at a dose of $1000 \mathrm{mg}$ twice daily for 6 months in addition to standard therapy, patients with standard therapy were group II. During the entire period of observation, there was no need to cancel the prescribed therapy due to side effects. According to the clinical course of the disease, concomitant pathology, the results of stress test of the group of patients were comparable and had no significant differences at the initial stage of observation (Table 3 ).

After 6 months ( \pm 10 days) from the beginning of the observation, an objective examination, echocardiography, exercise test, Holter-ECG monitoring of patients with slightly altered coronary arteries were repeated.

Statistical data processing was performed using Statistica 8.0 (StatSoft Inc, USA) and Excel 2003. With normal distribution, quantitative characteristics were presented as mean and standard deviation $(\mathrm{M} \pm \sigma)$, Student's criterion was used to compare the average of the two samples. Intergroup differences in qualitative traits were assessed using Pearson's $\chi 2$ test. For all types of analysis, the differences were considered statistically significant at $\mathrm{p}<0.05$. 


\section{Results}

According to the comparative analysis, it was found that in patients receiving in addition to standard therapy ranolazine (group I), 6 months after the prescribed therapy, statistically significantly longer $414.32 \pm 142.10 \mathrm{sec}$. was the duration of the test with exercise compared with initial test $356.51 \pm 180.24$ sec. $(\mathrm{p}=0.03)$. It was also found that the duration of the test in patients of group I after treatment was significantly different from patients of group II $380.5 \pm 152.2 \mathrm{sec}$ with a standard treatment regimen $(\mathrm{p}=0.04)$ (Table 2). According to the results of the survey, it was found in group I after treatment in $37.5 \%(n=6)$ patients was a positive test with exercise, and in group II after treatment $32.4 \%$ $(\mathrm{n}=12)$ patients.

We obtained a statistically significantly lower level of double product in group I before treatment, compared with after $(p=0.05)$. According to other indicators of the test with physical activity, the groups did not differ statistically (Table 3).

Table 3

Dynamics of stress test parameters in patients with INOCA

\begin{tabular}{|c|c|c|c|c|c|}
\hline Parameter & $\begin{array}{l}\text { Group I before } \\
\text { treatment } n=16\end{array}$ & $\begin{array}{l}\text { Group I after } \\
\text { treatment } n=16\end{array}$ & $\begin{array}{l}\text { Group II before } \\
\text { treatment } n=37\end{array}$ & $\begin{array}{c}\text { Group II after } \\
\text { treatment } \\
n=37\end{array}$ & $\mathrm{p}$ \\
\hline Positive test, n (\%) & $6(37.5)$ & $5(31.25)$ & $13(35.1)$ & $12(32.4)$ & $\begin{array}{c}\mathrm{p}_{1-3}=0.538 \\
\mathrm{p}_{1-2}=0.3 \\
\mathrm{p}_{3-4}=0.43 \\
\mathrm{p}_{2-4}=0.7\end{array}$ \\
\hline Negative test,n (\%) & $7(43.75)$ & $8(50)$ & $10(27)$ & $12(32.4)$ & $\begin{array}{l}\mathrm{p}_{1-3}=0.16 \\
\mathrm{p}_{1-2}=0.23 \\
\mathrm{p}_{3-4}=0.23 \\
\mathrm{p}_{2-4}=0.09\end{array}$ \\
\hline $\begin{array}{c}\text { Doubtful test, } \\
\text { n }(\%)\end{array}$ & 0 & 0 & $2(5.4)$ & $1(2.7)$ & $\begin{array}{l}\mathrm{p}_{1-3}=0.36 \\
\mathrm{p}_{3-4}=0.43\end{array}$ \\
\hline $\begin{array}{c}\text { ECG changes, n }(\%) \text { : } \\
- \text { ST segment depression } \\
- \text { ST segment elevation }\end{array}$ & $\begin{array}{c}3(18.75) \\
0\end{array}$ & $\begin{array}{c}3(18.75) \\
0\end{array}$ & $\begin{array}{c}7(18.9) \\
0\end{array}$ & $\begin{array}{c}7(18.9) \\
0\end{array}$ & $\begin{array}{l}\mathrm{p}_{1-3}=0.56 \\
\mathrm{p}_{1-2}=0.93 \\
\mathrm{p}_{3-4}=0.88 \\
\mathrm{p}_{2-4}=0.41\end{array}$ \\
\hline $\begin{array}{l}\text { Occurrence of typical } \\
\text { anginal pain, n }(\%)\end{array}$ & $2(12.5)$ & $2(12.5)$ & $4(10.8)$ & $4(10.8)$ & $\begin{array}{l}\mathrm{p}_{1-3}=0.36 \\
\mathrm{p}_{1-2}=0.99 \\
\mathrm{p}_{3-4}=0.98 \\
\mathrm{p}_{2-4}=0.41\end{array}$ \\
\hline $\begin{array}{l}\text { Combination of ECG } \\
\text { criteria + anginal pain }\end{array}$ & $1(6.25)$ & 0 & $2(5.4)$ & $2(5.4)$ & $\begin{array}{l}\mathrm{p}_{1-3}=0.6 \\
\mathrm{p}_{1-2}=0.53 \\
\mathrm{p}_{3-4}=0.78 \\
\mathrm{p}_{2-4}=0.41\end{array}$ \\
\hline Test duration, $\sec (\mathrm{M} \pm \sigma)$ & $356.51 \pm 180.24$ & $414.32 \pm 142.10^{*}$ & $361.4 \pm 160.24$ & $380.5 \pm 152.2 *$ & $\begin{array}{l}\mathrm{p}_{1-3}=0.53 \\
\mathrm{p}_{1-2}=0.03 \\
\mathrm{p}_{3-4}=0.15 \\
\mathrm{p}_{2-4}=0.04\end{array}$ \\
\hline $\begin{array}{l}\text { Double product, unit } \\
\qquad(\mathrm{M} \pm \sigma)\end{array}$ & $201.32 \pm 19.76$ & $178.84 \pm 17.90^{*}$ & $192.51 \pm 18.90$ & $181.5 \pm 20.2$ & $\begin{array}{l}\mathrm{p}_{1-3}=0.23 \\
\mathrm{p}_{1-2}=0.05 \\
\mathrm{p}_{3-4}=0.09 \\
\mathrm{p}_{2-4}=0.14\end{array}$ \\
\hline $\mathrm{IR}^{1}, \mathrm{~mm} \mathrm{H}$ & $39.53 \pm 28.76$ & $45.10 \pm 20.81$ & $41 \pm 18.81$ & $46 \pm 22.81$ & $\begin{array}{l}\mathrm{p}_{1-3}=0.53 \\
\mathrm{p}_{1-2}=0.23 \\
\mathrm{p}_{3-4}=0.15 \\
\mathrm{p}_{2-4}=0.41\end{array}$ \\
\hline $\mathrm{CR}^{2}$, beats/min & $40.04 \pm 25.13$ & $30.33 \pm 20.27$ & $42.20 \pm 25.13$ & $33.5 \pm 21.27$ & $\begin{array}{l}\mathrm{p}_{1-3}=0.06 \\
\mathrm{p}_{1-2}=0.23 \\
\mathrm{p}_{3-4}=0.08 \\
\mathrm{p}_{2-4}=0.41\end{array}$ \\
\hline $\begin{array}{l}\text { High tolerance to physi- } \\
\text { cal activity, n (\%) }\end{array}$ & $4 / 25$ & $5 / 31.3$ & $12 / 32.4$ & $10 / 27.02$ & $\begin{array}{l}\mathrm{p}_{1-3}=0.26 \\
\mathrm{p}_{1-2}=0.23 \\
\mathrm{p}_{3-4}=0.18 \\
\mathrm{p}_{2-4}=0.41\end{array}$ \\
\hline $\begin{array}{l}\text { Medium tolerance to } \\
\text { physical activity, n (\%) }\end{array}$ & $7 / 43.8$ & $8 / 50$ & $17 / 45.9$ & $20 / 54$ & $\begin{array}{l}\mathrm{p}_{1-3}=0.6 \\
\mathrm{p}_{1-2}=0.13 \\
\mathrm{p}_{3-4}=0.28 \\
\mathrm{p}_{2-4}=0.31\end{array}$ \\
\hline $\begin{array}{l}\text { Low tolerance to physi- } \\
\text { cal activity, n (\%) }\end{array}$ & $5 / 31.3$ & $2 / 12.5$ & $8 / 21.6$ & $7 / 18.9$ & $\begin{array}{l}\mathrm{p}_{1-3}=0.26 \\
\mathrm{p}_{1-2}=0.43 \\
\mathrm{p}_{3-4}=0.18 \\
\mathrm{p}_{2-4}=0.11\end{array}$ \\
\hline
\end{tabular}

Note: ${ }^{1}$ chronotropic reserve ${ }^{2}$ inotropic reserve; categorical indicators are given as the number of cases and the share, quantitative - as $M \pm \sigma$. The difference is statistically significant compared with those in patients of group I: ${ }^{*} p<0.05 ; * * p<0.01$ 
When comparing the level of tolerance to physical activity, it was found that in patients with ranolazine therapy, the proportion of patients with medium and high levels of tolerance to physical activity slightly increased (Fig. 1).

According to the results of Holter ECG in group I found a positive effect of ranolazine on the frequency of ventricular arrhythmias: before treatment $n=1142[30$; 2012], after treatment $n=729[23 ; 1420](p=0.02)$, while in group II a significant difference between the number of ventricular extrasystoles before treatment and after not detected $(n=1026[17 ; 1920], n=985$ [15; 1680], respectively) $\mathrm{p}=0.18$. There was a statistically significant decrease in the number of ventricular extrasystoles in group I after treatment, compared with the group with basic therapy (group II) $(\mathrm{p}=0.04)$.

In the analysis of echocardiography, it was found that after treatment groups of patients were statistically comparable (Table 5).

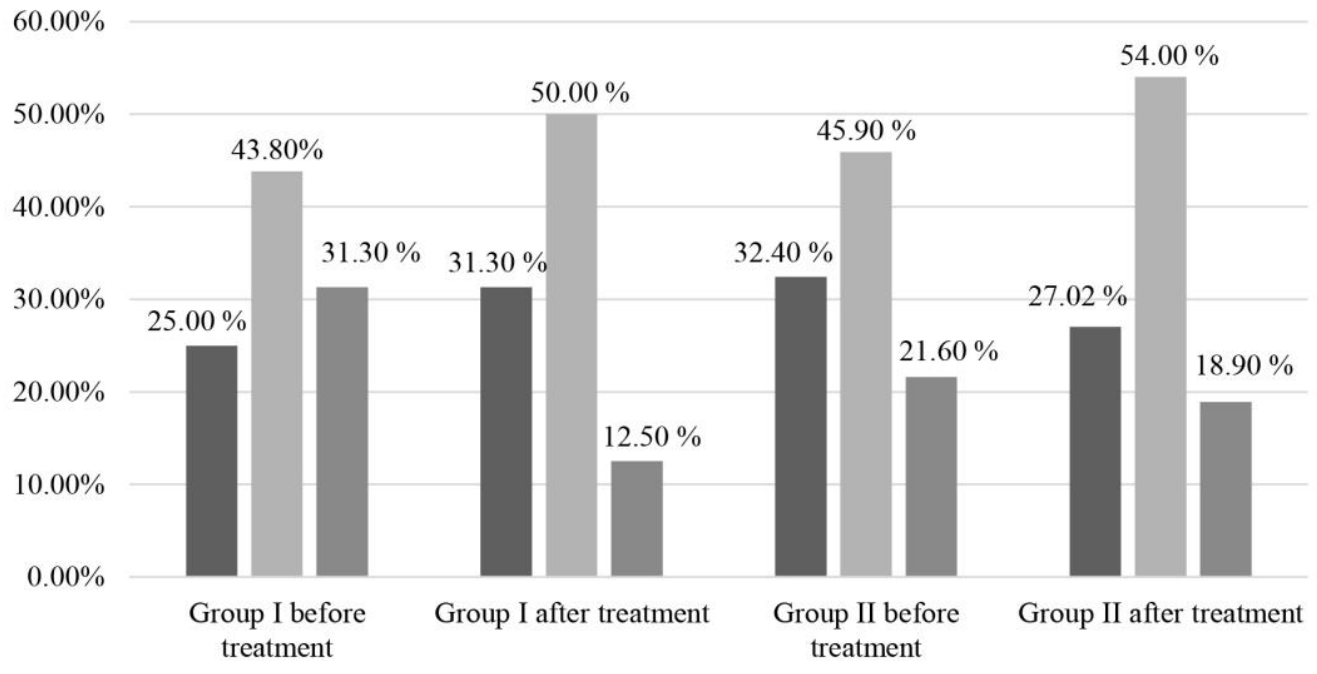

High tolerance to physical activity $\quad$ Medium tolerance to physical activity

n Low tolerance to physical activity

Fig. 1. Exercise tolerance in patients with INOCA

Table 4

Dynamics of Holter ECG in patients with INOCA

\begin{tabular}{|c|c|c|c|c|c|}
\hline Parameter & $\begin{array}{c}\text { Group I before treat- } \\
\text { ment } \mathrm{n}=16\end{array}$ & $\begin{array}{c}\text { Group I after } \\
\text { treatment } \mathrm{n}=16\end{array}$ & $\begin{array}{c}\text { Group II before } \\
\text { treatment } \mathrm{n}=37\end{array}$ & $\begin{array}{c}\text { Group II after } \\
\text { treatment } \mathrm{n}=37\end{array}$ & $\mathrm{p}$ \\
\hline $\mathrm{HB}^{1}$ per minute & $69.88 \pm 10.33$ & $66.2 \pm 10.1$ & $71.96 \pm 8.25$ & $67.5 \pm 9.2$ & $\begin{array}{l}\mathrm{p}_{1-3}=0.24 \\
\mathrm{p}_{1-2}=0.13 \\
\mathrm{p}_{3-4}=0.28 \\
\mathrm{p}_{2-4}=0.42\end{array}$ \\
\hline $\mathrm{SVE}^{2}$ & $169.3[0 ; 215]$ & $151.2[0 ; 163]$ & $136.5[0 ; 198]$ & $148.5[0 ; 168]$ & $\begin{array}{c}\mathrm{p}_{1-3}=0.34 \\
\mathrm{p}_{1-2}=0.23 \\
\mathrm{p}_{3-4}=0.28 \\
\mathrm{p}_{2-4}=0.62\end{array}$ \\
\hline PVCs & $1142[30 ; 2012]$ & $729[23 ; 1420]^{*}$ & $1026[17 ; 1920]$ & $985[15 ; 1680]^{*}$ & $\begin{array}{l}\mathrm{p}_{1-3}=0.26 \\
\mathrm{p}_{1-2}=0.02 \\
\mathrm{p}_{3-4}=0.18 \\
\mathrm{p}_{2-4}=0.04\end{array}$ \\
\hline $\begin{array}{c}\text { Depression of } \\
\text { ST segment, } \\
(\%)\end{array}$ & $10(62.5)$ & $8(50)$ & $24(64.8)$ & $20(54)$ & $\begin{array}{l}\mathrm{p}_{1-3}=0.44 \\
\mathrm{p}_{1-2}=0.23 \\
\mathrm{p}_{3-4}=0.18 \\
\mathrm{p}_{2-4}=0.32\end{array}$ \\
\hline $\begin{array}{c}\text { Duration of } \\
\text { episodes of } \\
\text { ischemia } \\
\text { minutes/days }\end{array}$ & $20.21 \pm 7.73$ & $15.15 \pm 5.53$ & $18.20 \pm 8.53$ & $15.04 \pm 6.12$ & $\begin{array}{l}\mathrm{p}_{1-3}=0.54 \\
\mathrm{p}_{1-2}=0.43 \\
\mathrm{p}_{3-4}=0.81 \\
\mathrm{p}_{2-4}=0.52\end{array}$ \\
\hline $\begin{array}{c}\text { Number of } \\
\text { episodes of } \\
\text { ischemia per } \\
\text { day }\end{array}$ & 2.6 & 2.2 & 2.8 & 2.6 & $\begin{array}{l}\mathrm{p}_{1-3}=0.54 \\
\mathrm{p}_{1-2}=0.63 \\
\mathrm{p}_{3-4}=0.28 \\
\mathrm{p}_{2-4}=0.42\end{array}$ \\
\hline
\end{tabular}

Note: ${ }^{1} \mathrm{HB}$ - heart beats, ${ }^{2} \mathrm{SVE}-$ supraventricular extrasystole, ${ }^{3} \mathrm{PVCs}$ - premature ventricular contractions 
Dynamics of echocardiography in patients with INOCA

\begin{tabular}{|c|c|c|c|c|}
\hline & \multicolumn{2}{|c|}{ Group I $(\mathrm{n}=16)$} & \multicolumn{2}{c|}{ Group II $(\mathrm{n}=37)$} \\
\hline Parameters & Before treatment & After treatment & Before treatment & After treatment \\
\hline LA $(\mathrm{cm})$ & $3.79 \pm 0.71$ & $3.85 \pm 0.51$ & $3.56 \pm 0.52$ & $3.66 \pm 0.52$ \\
\hline RA $(\mathrm{cm})$ & $3.59 \pm 0.39$ & $3.49 \pm 0.69$ & $3.63 \pm 0.41$ & $3.64 \pm 0.31$ \\
\hline LVDD(cm) & $4.75 \pm 0.41$ & $4.15 \pm 0.31$ & $4.25 \pm 0.65$ & $4.15 \pm 0.35$ \\
\hline LVDV ml & $98.20 \pm 34.2$ & $96.20 \pm 28.27$ & $95.09 \pm 33.73$ & $96.04 \pm 32.73$ \\
\hline LVSD(cm) & $3.23 \pm 0.33$ & $3.16 \pm 0.13$ & $3.31 \pm 0.71$ & $3.35 \pm 0.51$ \\
\hline LVSV ml & $39.66 \pm 15.05$ & $38.22 \pm 13.05$ & $37.10 \pm 14.98$ & $38.10 \pm 14.98$ \\
\hline RV & $2.34 \pm 0.24$ & $2.4 \pm 0.14$ & $2.47 \pm 0.44$ & $2.44 \pm 0.44$ \\
\hline SWS & $0.99 \pm 0.12$ & $0.98 \pm 0.22$ & $1.01 \pm 0.14$ & $1.01 \pm 0.14$ \\
\hline PWS & $0.98 \pm 0.11$ & $0.99 \pm 0.15$ & $1.03 \pm 0.18$ & $1.03 \pm 0.18$ \\
\hline FE, \% & $60.35 \pm 4.99$ & $60.95 \pm 4.99$ & $63.54 \pm 3.58$ & $62.54 \pm 3.8$ \\
\hline E/A & $0.98 \pm 0.46$ & $0.92 \pm 0.36$ & $1.01 \pm 0.26$ & $1.08 \pm 0.16$ \\
\hline Ve $(\mathrm{cm})$ & $75.50 \pm 19.34$ & $74.50 \pm 15.34$ & $77.13 \pm 14.59$ & $76.28 \pm 15.34$ \\
\hline
\end{tabular}

\section{Discussion}

According to the results of the study, we found an increase in exercise tolerance with prolongation of the duration of the stress test to the development of myocardial ischemia on clinical and/or ECG signs on the additional therapy with ranolazine. Thomas Kofler, in his work, confirms that ranolazine increases the reserve of coronary blood flow, reduces the clinical manifestations of angina and improves physical activity and quality of life. However, it is not known whether it improves the long-term prognosis of such patients [13]. Studies by Bernard R. Chaitman have confirmed that ranolazine increases the time to onset of ischemia during treadmill test, improves exercise duration, reduces the incidence of high-symptomatic angina, and is recommended for the treatment of chronic angina patients with obstructive coronary heart disease who have persistent symptoms despite optimal drug treatment $[14,15]$. In the WISE study with ranolazine in microvascular dysfunction, it was found that patients with reduced baseline coronary fraction reserve $(<2.5)$ were most likely to have benefit from ranolazine with a significant improvement in myocardial perfusion and angina [16]. This was also recently shown by a comprehensive meta-analysis of Zhu et al., which predicted increased efficacy of ranolazine in subgroups of microvascular dysfunction with a baseline coronary fractional reserve <2.5 [17]. Tagliamonte et al. found the most consistent benefit of ranolazine in terms of improving quality of life according to the SAQ questionnaire. This can be explained by the fact that their study had the longest mean follow-up period (8 weeks). In contrast to patients with stenotic atherosclerosis, patients with microvascular dysfunction may need a longer duration of treatment to get the optimal benefits from ranolazine [18].

We also found a significant decrease in the number of ventricular arrhythmias in patients with INOCA after treatment, which is confirmed by the results of other studies [19, 20].
Study limitations. Restrictions due to the involvement of small sample of patients.

Prospects for future research. It would be interesting to conduct the study for a longer time and with a larger cohort of participants in patients with nonobstructive CAD. To evaluate the effect of ranolazine on the long-term prognosis in such patients.

\section{Conclusions}

1. Patients with INOCA, who had additionally to basic therapy ranolazine for 6 months had a significant increase in exercise tolerance with prolongation of the duration of the stress test to the development of myocardial ischemia on clinical and/or ECG signs $(414.32 \pm 142.10 \mathrm{sec})$ in comparison with the initial parameters $(356.51 \pm 180.24 \mathrm{sec})$ and with the parameters in the group with basic therapy $380.5 \pm 152.2$ ( $\mathrm{p}=0.03$ and $\mathrm{p}=0.04$, respectively).

2. Complementation of basic therapy by ranolazine contributes to a significant reduction of the number of ventricular arrhythmias in patients with coronary heart disease with non-obstructive coronary arteries $\mathrm{n}=729$ [23; 1420] compared with baseline $\mathrm{n}=1142$ [30; 2012] ( $\mathrm{p}=0.02)$, while in patients with only basic therapy (group II) a significant decrease in the frequency of ventricular extrasystoles was not detected $(n=1026$ [17; 1920] against $n=995[15 ; 1680])(p=0.18)$

\section{Conflict of interests}

The authors declare that they have no conflicts of interest.

\section{Financing}

The study was performed without financial support.

\section{Acknowledgments}

We express our gratitude to the patients who took part in the study, as well as the specialists who contributed to the investigation

\section{References}

1.Ma, J., Chen, X. (2021). Anti-inflammatory Therapy for Coronary Atherosclerotic Heart Disease: Unanswered Questions Behind Existing Successes. Frontiers in Cardiovascular Medicine, 7. doi: http://doi.org/10.3389/fcvm.2020.631398 
2.Douglas, P. S., Hoffmann, U., Patel, M. R., Mark, D. B., Al-Khalidi, H. R., Cavanaugh, B. et. al. (2015). Outcomes of Anatomical versus Functional Testing for Coronary Artery Disease. New England Journal of Medicine, 372 (14), 1291-1300. doi: http://doi.org/10.1056/nejmoa1415516

3.Camici, P. G., Crea, F. (2007). Coronary Microvascular Dysfunction. New England Journal of Medicine, 356 (8), $830-840$. doi: http://doi.org/10.1056/nejmra061889

4.Kaski, J.-C., Crea, F., Gersh, B. J., Camici, P. G. (2018). Reappraisal of Ischemic Heart Disease. Circulation, 138 (14), 1463-1480. doi: http://doi.org/10.1161/circulationaha.118.031373

5.Nishi, T., Murai, T., Ciccarelli, G., Shah, S. V., Kobayashi, Y., Derimay, F. et. al. (2019). Prognostic Value of Coronary Microvascular Function Measured Immediately After Percutaneous Coronary Intervention in Stable Coronary Artery Disease. Circulation: Cardiovascular Interventions, 12 (9). doi: http://doi.org/10.1161/circinterventions.119.007889

6.Agewall, S., Beltrame, J. F., Reynolds, H. R., Niessner, A., Rosano, G., Caforio, A. L. P. et. al. (2016). ESC working group position paper on myocardial infarction with non-obstructive coronary arteries. European Heart Journal, 38, 143-153. doi: http://doi.org/10.1093/eurheartj/ehw149

7.Rayner- Hartley, E., Sedlak, T. (2016). Ranolazine: A Contemporary Review. Journal of the American Heart Association, 5 (3). doi: http://doi.org/10.1161/jaha.116.003196

8.Zhu, H., Xu, X., Fang, X., Zheng, J., Zhao, Q., Chen, T., Huang, J. (2019). Effects of the Antianginal Drugs Ranolazine, Nicorandil, and Ivabradine on Coronary Microvascular Function in Patients With Nonobstructive Coronary Artery Disease: A Meta-analysis of Randomized Controlled Trials. Clinical Therapeutics, 41 (10), 2137-2152.e12. doi: http://doi.org/10.1016/j.clinthera.2019.08.008

9.Knuuti, J., Wijns, W., Saraste, A., Capodanno, D., Barbato, E., Funck-Brentano, C. et. al. (2019). 2019 ESC Guidelines for the diagnosis and management of chronic coronary syndromes. European Heart Journal, 41 (3), 407-477. doi: http://doi.org/10.1093/ eurheartj/ehz425

10. Inobe, Y., Kugiyama, K., Morita, E., Kawano, H., Okumura, K., Tomiguchi, S. et. al. (1996). Role of Adenosine in Pathogenesis of Syndrome X: Assessment With Coronary Hemodynamic Measurements and Thallium-201 Myocardial Single-Photon Emission Computed Tomography. Journal of the American College of Cardiology, 28 (4), 890-896. doi: http://doi.org/10.1016/s0735-1097(96)00271-9

11. Zharinov, O., Ivanov, Yu., Kitch, V. (Eds.) (2021). Funktsionalna diahnostyka. Kyiv: Chetverta khvylia, 784.

Zharinov, O. J., Kitch, V. O., Thor, N. V. (2006). Navantazhuvalni proby v kardiolohii. Kyiv: Medytsyna svitu, 89.

12. Unifikovanyi klinichnyi protokol pervynnoi, vtorynnoi (spetsializovanoi) ta tretynnoi (vysokospetsializovanoi) medychnoi dopomohy «Stabilna ishemichna khvoroba sertsia» (2016). Nakaz Ministerstva okhorony zdorovia Ukrainy No. 152. 02.03.2016. Available at: https://neuronews.com.ua/ru/files/1865170518.pdf

13. Kofler, T., Hess, S., Moccetti, F., Pepine, C. J., Attinger, A., Wolfrum, M. et. al. (2021). Efficacy of Ranolazine for Treatment of Coronary Microvascular Dysfunction - A Systematic Review and Meta-analysis of Randomized Trials. CJC Open, 3 (1), 101-108. doi: http://doi.org/10.1016/j.cjco.2020.09.005

14. Chaitman, B. R., Skettino, S. L., Parker, J. O., Hanley, P., Meluzin, J., Kuch, J. et. al. (2004). Anti-ischemic effects and long-term survival during ranolazine monotherapy in patients with chronic severe angina. Journal of the American College of Cardiology, 43 (8), 1375-1382. doi: http://doi.org/10.1016/j.jacc.2003.11.045

15. Bairey Merz, C. N., Handberg, E. M., Shufelt, C. L., Mehta, P. K., Minissian, M. B., Wei, J. et. al. (2015). A randomized, placebo-controlled trial of late Na current inhibition (ranolazine) in coronary microvascular dysfunction (CMD): impact on angina and myocardial perfusion reserve. European Heart Journal, 37 (19), 1504-1513. doi: http://doi.org/10.1093/eurheartj/ehv647

16. Zhu, H., Xu, X., Fang, X., Zheng, J., Zhao, Q., Chen, T., Huang, J. (2019). Effects of the Antianginal Drugs Ranolazine, Nicorandil, and Ivabradine on Coronary Microvascular Function in Patients With Nonobstructive Coronary Artery Disease: A Meta-analysis of Randomized Controlled Trials. Clinical Therapeutics, 41 (10), 2137-2152.e12. doi: http://doi.org/10.1016/j.clinthera.2019.08.008

17. Aguilar, J., Wei, J., Quesada, O., Shufelt, C., Bairey Merz, C. N. (2021). Coronary Microvascular Dysfunction. Sex Differences in Cardiac Diseases. Elsevier, 141-158. doi: http://doi.org/10.1016/b978-0-12-819369-3.00021-6

18. Curnis, A., Salghetti, F., Cerini, M., Vizzardi, E., Sciatti, E., Vassanelli, F. et. al. (2017). Ranolazine therapy in drug-refractory ventricular arrhythmias. Journal of Cardiovascular Medicine, 18 (7), 534-538. doi: http://doi.org/10.2459/jcm.0000000000000521

19. Shah, N. R., Cheezum, M. K., Veeranna, V., Horgan, S. J., Taqueti, V. R., Murthy, V. L. et. al. (2017). Ranolazine in Symptomatic Diabetic Patients Without Obstructive Coronary Artery Disease: Impact on Microvascular and Diastolic Function. Journal of the American Heart Association, 6 (5). doi: http://doi.org/10.1161/jaha.116.005027

Received date 27.07.2021

Accepted date 24.08.2021

Published date 30.09.2021

Vira Tseluyko, Doctor of Medical Sciences, Professor, Head of Department, Honored Scientist and of Technology of Ukraine, Department of Cardiology and Functional Diagnostics, V. N. Karazin Kharkiv National University, Svobody sq., 4, Kharkiv, Ukraine, 61022

Tetyana Pylova*, Postgraduate Student, Department of Cardiology and Functional Diagnostics, Kharkiv Medical Academy of Postgraduate Education, Amosova str., 58, Kharkiv, Ukraine, 61176

*Corresponding author: Tetyana Pylova, e-mail: pylovatanya@gmail.com 